\title{
The prevalence of orthostatic hypotension during physiotherapy treatment in patients with an acute spinal cord injury
}

\author{
A Illman*,1, K Stiller ${ }^{1}$ and M Williams ${ }^{1}$ \\ ${ }^{1}$ Physiotherapy Department, Hampstead Rehabilitation Centre, Northfield, South Australia, Australia
}

\begin{abstract}
Study design: Prospective, observational.
Objectives: To investigate the prevalence of orthostatic hypotension $(\mathrm{OH})$, its associated signs and symptoms, and the resulting limitation to treatment during initial physiotherapy treatments involving mobilisation for patients with an acute spinal cord injury (SCI).

Setting: Spinal Injuries Units, Royal Adelaide Hospital and Hampstead Rehabilitation Centre, Adelaide, South Australia.

Methods: Fourteen of 17 consecutive patients admitted with an acute SCI completed the study. Non-invasive measurement of systolic and diastolic blood pressure (BP), heart rate and percutaneous oxygen saturation were recorded during a 10-min baseline period with the patient resting in supine, and then at 1-min intervals for the first 10 min of physiotherapy treatments that involved mobilisation (ie sitting or standing). Following cessation of the treatment and return to the supine position, further measurements were made immediately and following $5 \mathrm{~min}$ of rest. Visual signs and patient reported symptoms of $\mathrm{OH}$ and any perceived limitation to therapy were also recorded. The study period comprised the first 10 physiotherapy treatments that involved mobilisation.

Results: BP changes indicative of $\mathrm{OH}$ occurred during $73.6 \%$ of mobilisation treatments. Of these treatments, accompanying signs and symptoms of $\mathrm{OH}$ were noted on $58.9 \%$ of occasions and were perceived as limiting treatment on $43.2 \%$ of occasions. Patients with tetraplegia had a higher prevalence of $\mathrm{OH}$ and a greater fall in $\mathrm{BP}$ than patients with paraplegia, irrespective of whether their lesion was complete or incomplete.

Conclusion: Blood pressure changes indicative of $\mathrm{OH}$ and accompanying signs and symptoms of $\mathrm{OH}$ are a common occurrence during the physiotherapy mobilisation of patients with an acute SCI.
\end{abstract}

Spinal Cord (2000) 38, $741-747$

Keywords: spinal cord injury; tetraplegia; paraplegia; hypotension; orthostatic; physical therapy

\section{Introduction \\ Orthostatic hypotension $(\mathrm{OH})$ refers to a significant decrease in blood pressure (BP) on assuming an upright posture. While the precise definition of $\mathrm{OH}$ is variable, the American Autonomic Society and American Academy of Neurology ${ }^{1}$ achieved consensus in defining $\mathrm{OH}$ as a reduction in systolic $\mathrm{BP}$ of at least $20 \mathrm{mmHg}$ or diastolic BP of at least $10 \mathrm{mmHg}$ within 3 min of standing or being raised greater than $60^{\circ}$ on a tilt table. Orthostatic hypotension may be symptomatic or asymptomatic, with symptoms including light- headedness, dizziness, blurred vision, ringing in the ears, nausea, fatigue, cognitive impairment, palpita- tions, tremulousness, headache and neck ache. ${ }^{1}$}

*Correspondence: A Illman, Physiotherapy Department, Hampstead Rehabilitation Centre, Hampstead Road, Northfield, South Australia 5085, Australia
Orthostatic hypotension is described as being a common occurrence in patients who have sustained a spinal cord injury (SCI), as the injury to the spinal cord interferes with the normal transmission of the sympathetic nervous system messages which provide short term regulation of $\mathrm{BP}^{2-4}$ As $\mathrm{OH}$ can restrict patients from fully participating in rehabilitation, it has the potential to delay the achievement of rehabilitation goals and to increase the length of hospitalisation. ${ }^{2}$ There is also limited evidence that $\mathrm{OH}$ can lead to neurological deterioration in patients with a biomechanically stable SCI. ${ }^{5}$

Despite there being a general belief that $\mathrm{OH}$ is a common occurrence in the acute SCI patient population, no published studies specifically investigating the prevalence of $\mathrm{OH}$ and the resulting limitation on rehabilitation were found for patients with acute SCI. The aim of this study was to document the prevalence 
of $\mathrm{OH}$ during physiotherapy treatment involving mobilisation, its associated symptoms and signs, and the resulting limitation to treatment in patients presenting with an acute SCI.

\section{Methods}

Consecutive patients admitted to the Royal Adelaide Hospital Spinal Injuries Unit from May to November 1998 with an acute SCI who gave their written informed consent were eligible for inclusion in the study. Patients unwilling to participate or unable to understand written or spoken English were excluded. Patients transferred to another hospital (apart from Hampstead Rehabilitation Centre) prior to completion of data collection were withdrawn from the study. Patients that were transferred from the Spinal Injuries Unit at the acute hospital setting (Royal Adelaide Hospital) to the Spinal Injuries Unit at the rehabilitation setting (Hampstead Rehabilitation Centre) remained in the study.

Each patient's age, sex, past medical history, level of SCI, American Spinal Injury Association (ASIA) impairment scale level, ${ }^{6}$ additional injuries, spinal reflexes and medications were recorded from the casenotes. In addition, the number of days of bed rest prior to commencement of mobilisation was noted.

Once mobilisation was approved by medical staff, each patient was placed in the supine position. The patency of the urinary catheter was checked to avoid the possibility of bladder distension affecting BP. ${ }^{7}$ Anti-embolic stockings were worn by all patients throughout testing, and abdominal binders were used for patients with complete motor tetraplegia, as per the Royal Adelaide Hospital Spinal Injuries Unit protocol. If directed by medical staff, external spinal bracing was applied. The treatment procedure was explained to the patient prior to commencement of the treatment. As the study was observational, the frequency of treatment varied between patients according to their medical condition. Frequency of treatment ranged from once to twice a day for most patients and did not always occur on consecutive days.

\section{Treatment procedure}

The patient lay quietly in a supine position with the bed flat for $10 \mathrm{~min}$ while baseline resting data were obtained. The patient was then slowly brought to an upright sitting position on the edge of the bed with the assistance of one or two physiotherapists. Sitting balance, transfers, standing and/or gait re-education was then performed according to the individual patient's capabilities. This treatment continued for the length of time tolerated by the patient, as per usual clinical practice. At the cessation of treatment, the patient was returned to the supine position, with the bed flat, and kept resting in this position for $5 \mathrm{~min}$ while further data were recorded.
In separate treatment sessions, the physiotherapist performed stretching and range of movement exercises for patients, and assisted with strengthening exercises, with the patient positioned in supine. Blood pressure was not measured during these separate sessions nor during usual nursing care procedures such as showering and feeding.

\section{Measurement procedure}

Measurements recorded for the purpose of the study comprised systolic BP, diastolic BP, heart rate (HR) percutaneous oxygen saturation $\left(\mathrm{SpO}_{2}\right)$, the visual signs and patient reported symptoms of $\mathrm{OH}$, and the perceived limitation of treatment due to $\mathrm{OH}$. Measurements were made every 5 min during the initial 10 -min baseline resting period and then at 1-min intervals for the first $10 \mathrm{~min}$ of treatment (or part thereof if the patient did not tolerate treatment for the full $10 \mathrm{~min}$ ). Further measurements were taken immediately after cessation of treatment and resumption of the supine position, and then again 5 min later. Measurements were obtained for the first 10 treatments for each patient that involved mobilisation by physiotherapists.

The definition of $\mathrm{OH}$ by the American Autonomic Society and American Academy of Neurology 1 was modified for the purpose of this study. As patients with SCI are not necessarily able to stand and, in our Spinal Injuries Unit, do not routinely receive tilting on a tilt table, it was decided to document the occurrence of $\mathrm{OH}$ during the change in position from supine to either sitting or standing. Furthermore, rather than documenting $\mathrm{OH}$ for the first 3 min of attaining an upright position, this was extended to the first $10 \mathrm{~min}$ of treatment as it was anticipated from previous experience that delayed $\mathrm{OH}$ may occur in this patient population. ${ }^{8}$ The specific reduction in systolic and diastolic BP required to be classified as $\mathrm{OH}$ remained as described by the American Autonomic Society and American Academy of Neurology (ie a reduction in systolic BP of at least $20 \mathrm{mmHg}$ or diastolic BP of at least $10 \mathrm{mmHg})^{1}$

A calibrated Dinamap ${ }^{\text {TM }} 9720$ monitor was set up by one of two physiotherapists not involved in treating the particular patient, in accordance to the manufacturer's recommendation, to measure systolic and diastolic $\mathrm{BP}, \mathrm{HR}$ and $\mathrm{SpO}_{2}$. To ensure a standard protocol for measuring these data, the brachial artery was palpated and the cuff was placed firmly around the patient's bare left arm. The lower end of the cuff was positioned approximately $2 \mathrm{~cm}$ above the cubital fossa. Care was taken to ensure that the correct sized cuff was selected for each patient, based on arm circumference, and this cuff was then used throughout data collection for that patient. The oximeter probe was placed on the patient's left ear lobe and secured in place with tape. A printer attached to the Dinamap ${ }^{\mathrm{TM}}$ 9720 monitor recorded the measurements.

The treating physiotherapist documented the occurrence of signs of $\mathrm{OH}$ that were evident visually, 
namely pallor, sweating and loss of consciousness, and questioned patients regularly about symptoms of $\mathrm{OH}$ (ie dizziness, light-headedness, nausea, visual changes, ringing or buzzing in the ears). In addition, the treating physiotherapist recorded occasions when she/ he perceived $\mathrm{OH}$ as limiting treatment. The treating physiotherapist was unaware of the results of the measurements of $\mathrm{BP}, \mathrm{HR}$ and $\mathrm{SpO}_{2}$ throughout the study period.

To ensure that the measurements obtained with the Dinamap $^{\text {TM }} 9720$ monitor were accurate, systolic BP, diastolic BP and heart rate from the Dinamap ${ }^{\mathrm{TM}} 9720$ monitor were simultaneously compared to invasive intra-arterial BP monitoring and ECG recordings. Ten measurements were taken at approximately 1-min intervals on a sample of convenience, comprised of five patients in the Intensive Care Unit who had preexisting intra-arterial BP monitoring. Intra-class correlation values $(1,1)$ of at least 0.90 were found, indicating high consistency between the two types of monitoring.

\section{Analyses \\ For the purpose of analysis, mean values for the entire group were calculated. In addition, individual patient data were examined in an attempt to identify features associated with the development of $\mathrm{OH}$. Due to the small sample size, statistical analysis was not considered appropriate.}

\section{Results}

Seventeen consecutive patients admitted to the Royal Adelaide Hospital Spinal Injuries Unit were eligible for inclusion in the study. Two patients were excluded from the study - both patients could not give informed consent due to a closed head injury for one patient and impaired cognitive ability for the second patient. A further patient was withdrawn from the study as he was transferred to another hospital prior to completion of data collection. Thus, 14 patients completed the study.

Descriptive data for the 14 patient that completed the study are presented in Table 1. As all patients were receiving numerous medications, these have not been listed in the Table, but they commonly included analgesia (morphine, Panadeine Forte or codeine phosphate) and aperients (Micralax and /or coloxyl with senna). Some patients also received medications such as steroids, antibiotics, bronchodilators and/or anticoagulants. Two patients (patient numbers 1 and 4) were discharged home after five mobilisation treatments, and for one patient (patient number 7) data collection was incomplete for one of the 10 treatments. The data from these patients have been included in analyses.

The mean values for systolic and diastolic BP for the 14 patients considered together, averaged over the treatments that comprised the study period, are shown in Figure 1. As can be seen, the mean systolic BP was stable during the baseline rest period, fell during the mobilisation treatment period and returned to baseline levels soon after resumption of the resting position (Figure 1). The maximum fall in mean systolic BP $(21.0 \mathrm{mmHg})$ during the treatment period from the mean of the three baseline readings, was sufficient to meet the criterion for $\mathrm{OH}$. Mean diastolic BP also fell during the treatment period, however the maximum fall $(7.2 \mathrm{mmHg})$ was not sufficient to be defined as $\mathrm{OH}$. Mean HR was stable during the initial baseline period (73.8 beats per minute), increased by a maximum of 14.9 beats per minute during the treatment period and returned to near resting values on resumption of the supine position. The mean $\mathrm{SpO}_{2}$ showed little change throughout the study period (mean value: $97.1 \%$ during baseline period, 96.6\% during treatment period). For the sake of brevity, HR and $\mathrm{SpO}_{2}$ data have not been presented

In order to simplify data presentation, all the variables collected for each subject during each treatment have not been presented. Instead, a summary of the data collected for individual patients is presented in Table 2. As can be seen, $\mathrm{OH}$ as defined by BP measurements occurred for all patients on at least one treatment occasion. Out of the total of 129 treatments where $\mathrm{BP}$ was measured, $\mathrm{OH}$ occurred during 95 treatments $(73.6 \%$ of treatments). Of these 95 treatments, visual signs and patient reported symptoms of $\mathrm{OH}$ were also noted for 56 treatments $(58.9 \%)$. Treatment was perceived as being limited due to $\mathrm{OH}$ on 43 of the total of 129 treatments $(33.3 \%)$, which included 41 of the 95 treatments $(43.2 \%)$ when $\mathrm{BP}$ changes indicative of $\mathrm{OH}$ were noted. On all occasions when treatment was perceived as being limited by $\mathrm{OH}$, visual signs and symptoms of $\mathrm{OH}$ were present. On four occasions (three occasions for patient number 1 and once for patient number 14) visual signs and symptoms of $\mathrm{OH}$ were noted, but were not accompanied by a fall in BP indicative of $\mathrm{OH}$. When $\mathrm{OH}$ occurred a fall in both systolic and diastolic BP was seen on $73.7 \%$ of occasions, with a fall in either systolic or diastolic BP (but not both) relatively evenly spread over the remaining occasions. Only two patients (patient numbers 1 and 4) demonstrated rebound hypertension (of more than $10.0 \mathrm{mmHg}$ ) when they were returned to the supine position at the completion of the treatment period.

To ascertain whether patients with tetraplegia were more prone to $\mathrm{OH}$ than patients with paraplegia, patients were allocated to one of two groups according to the level of their lesion. Any patient with a cervical spinal cord lesion was considered to have tetraplegia (10 patients) and the remaining patients (4 patients) were classified as having paraplegia. Figure 2 shows the mean BP for patients according to this classification. The patients with paraplegia had a small decrease in systolic BP, not sufficient to classify as $\mathrm{OH}$, and a small increase in diastolic BP during treatment. Patients with tetraplegia however, showed a marked 
Table 1 Descriptive data for the 14 patients completing the study

\begin{tabular}{|c|c|c|c|c|c|c|c|}
\hline $\begin{array}{l}\text { Patient } \\
\text { number }\end{array}$ & $\begin{array}{c}\text { Age (years) } \\
\text { /Sex }\end{array}$ & $\begin{array}{l}\text { Past } \\
\text { medical } \\
\text { history }\end{array}$ & $\begin{array}{l}\text { Level of } \\
\text { spinal cord } \\
\text { injury }\end{array}$ & $\begin{array}{c}\text { ASIA } \\
\text { impairment } \\
\text { scale }\end{array}$ & $\begin{array}{l}\text { Presence } \\
\text { of spinal } \\
\text { reflexes }\end{array}$ & $\begin{array}{l}\text { Additional } \\
\text { injuries }\end{array}$ & $\begin{array}{l}\text { Number of days } \\
\text { of bed rest prior } \\
\text { to mobilisation }\end{array}$ \\
\hline 1 & $38 / \mathrm{M}$ & Nil & $\mathrm{C} 7$ & $\mathrm{D}$ & Yes & Nil & 4 \\
\hline 2 & 43/M & Nil & T12 & A & No & Nil & 10 \\
\hline 3 & $46 / F$ & Oesophagitis & $\mathrm{T} 10$ & A & Yes & $\begin{array}{l}\text { Haemothoraces, fractured } \\
\text { acetabulum, mild CHI }\end{array}$ & 45 \\
\hline 4 & $18 / \mathrm{M}$ & Drug abuse & L3 & $\mathrm{D}$ & Yes & Nil & 4 \\
\hline 5 & $16 / \mathrm{M}$ & Asthma & $\mathrm{C} 5$ & A & Yes & Nil & 24 \\
\hline 6 & $44 / \mathrm{M}$ & Asthma & C5 & $\mathrm{D}$ & Yes & $\begin{array}{l}\text { Fractured ribs, pneumothorax } \\
\text { liver haematoma, DVT }\end{array}$ & 12 \\
\hline 7 & $45 / \mathrm{M}$ & Nil & L2 & $\mathrm{B}$ & No & Nil & 13 \\
\hline 8 & $32 / \mathrm{F}$ & Nil & $\mathrm{C} 2$ & $\mathrm{D}$ & Yes & $\begin{array}{c}\text { Fractured ribs, L1-3 } \\
\text { clavicle, haemothorax, mild CHI }\end{array}$ & 24 \\
\hline 9 & $17 / F$ & Asthma & C6 & $\mathrm{D}$ & Yes & Perforated bowel & 12 \\
\hline 10 & $75 / F$ & Cardiomegaly & C6 & $\mathrm{D}$ & Yes & Fractured T3-6 & 3 \\
\hline 11 & $30 / \mathrm{M}$ & Thalassemia & $\mathrm{C} 5$ & A & Yes & Nil & 20 \\
\hline 12 & $36 / \mathrm{M}$ & Nil & $\mathrm{C} 4$ & A & Yes & Nil & 17 \\
\hline 13 & $19 / \mathrm{M}$ & Nil & $\mathrm{C} 5$ & B & No & Nil & 17 \\
\hline 14 & $27 / \mathrm{M}$ & Nil & $\mathrm{C} 5$ & $\mathrm{~B}$ & Yes & Nil & 15 \\
\hline
\end{tabular}

ASIA = American Spinal Injury Association; $\mathrm{M}=$ male; $\mathrm{F}=$ female; $\mathrm{C}=$ cervical; $\mathrm{T}=$ thoracic; $\mathrm{L}=$ lumbar; $\mathrm{CHI}=$ closed head injury; DVT $=$ deep vein thrombosis.

\section{ASIA impairment scale: ${ }^{6}$}

$\mathrm{A}=$ complete (no motor or sensory function preserved in the sacral segments $\mathrm{S} 4-\mathrm{S} 5$ );

$\mathrm{B}=$ incomplete (sensory but not motor function below the neurological level and extends through the segments S4-S5);

$\mathrm{C}=$ incomplete (motor function is preserved below the neurological level and the majority of key muscles below the neurological level have a muscle grade less than three);

$\mathrm{D}=$ incomplete (motor function is preserved below the neurological level and the majority of key muscles below the neurological level have a muscle grade greater or equal to three);

$\mathrm{E}=$ normal (motor and sensory function is normal)

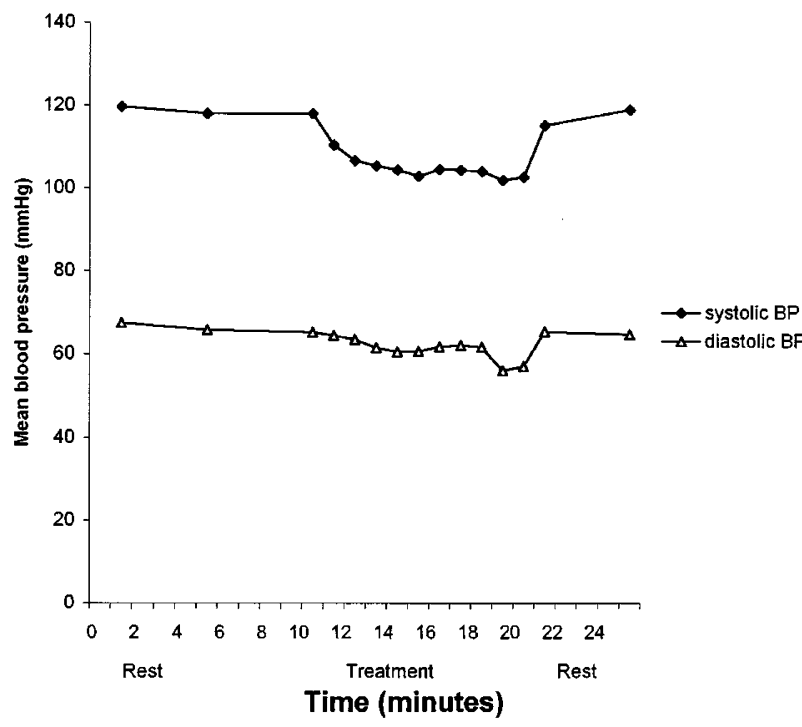

Figure 1 Mean systolic and diastolic blood pressure for the 14 patients

fall in systolic BP, which was of sufficient magnitude to classify as $\mathrm{OH}$, and a less marked fall in diastolic BP during treatment. As far as the prevalence of $\mathrm{OH}$ was concerned, $\mathrm{OH}$ occurred during 78 of the 95
Table 2 Summary of outcome data for the 14 patients completing the study

\begin{tabular}{lcccccccccc}
\hline Patient & \multicolumn{1}{c}{ Treatment number } & & & & \\
number & 1 & 2 & 3 & 4 & 5 & 6 & 7 & 8 & 9 & 10 \\
\hline 1 & $\mathrm{SL}$ & $\mathrm{S}$ & $\mathrm{S}$ & $\mathrm{S}$ & & $\mathrm{X}$ & $\mathrm{X}$ & $\mathrm{X}$ & $\mathrm{X}$ & $\mathrm{X}$ \\
2 & & & & & & & & & & \\
3 & & & & & & & & & & \\
4 & & & & & & $\mathrm{X}$ & $\mathrm{X}$ & $\mathrm{X}$ & $\mathrm{X}$ & $\mathrm{X}$ \\
5 & $\mathrm{SL}$ & $\mathrm{SL}$ & $\mathrm{SL}$ & $\mathrm{SL}$ & $\mathrm{SL}$ & $\mathrm{SL}$ & $\mathrm{SL}$ & $\mathrm{SL}$ & $\mathrm{SL}$ & $\mathrm{SL}$ \\
6 & $\mathrm{SL}$ & $\mathrm{SL}$ & $\mathrm{SL}$ & $\mathrm{S}$ & $\mathrm{S}$ & $\mathrm{SL}$ & $\mathrm{SL}$ & $\mathrm{SL}$ & & \\
7 & $\mathrm{SL}$ & & & & & & & & & \\
8 & & & & & & & & & & \\
9 & $\mathrm{SL}$ & $\mathrm{SL}$ & $\mathrm{SL}$ & $\mathrm{SL}$ & $\mathrm{SL}$ & $\mathrm{SL}$ & & & & \\
10 & $\mathrm{SL}$ & $\mathrm{SL}$ & & & & & & & & \\
11 & $\mathrm{SL}$ & $\mathrm{SL}$ & $\mathrm{SL}$ & $\mathrm{SL}$ & $\mathrm{SL}$ & $\mathrm{SL}$ & $\mathrm{SL}$ & $\mathrm{SL}$ & $\mathrm{SL}$ & $\mathrm{SL}$ \\
12 & $\mathrm{~S}$ & $\mathrm{~S}$ & $\mathrm{~S}$ & $\mathrm{~S}$ & $\mathrm{SL}$ & $\mathrm{S}$ & $\mathrm{S}$ & & & \\
13 & $\mathrm{SL}$ & $\mathrm{SL}$ & $\mathrm{S}$ & $\mathrm{S}$ & & & & & & \\
14 & $\mathrm{SL}$ & $\mathrm{SL}$ & $\mathrm{SL}$ & $\mathrm{SL}$ & & $\mathrm{S}$ & $\mathrm{S}$ & $\mathrm{S}$ & $\mathrm{S}$ & $\mathrm{S}$ \\
\hline
\end{tabular}

*BP data unavailable. S, visual signs and/or patient reported symptoms of $\mathrm{OH}$. L, perceived limitation to treatment because of $\mathrm{OH}$. Shaded areas represent treatments when $\mathrm{OH}$ was present as defined by $\mathrm{BP}$ changes. $\mathrm{X}$, no treatment performed - patient discharged from hospital

treatments $(82.1 \%)$ that the patients with tetraplegia received, compared to 17 of the 34 treatments $(50.0 \%)$ that patients with paraplegia received. Visual signs and patient reported symptoms of $\mathrm{OH}$ were noted during 


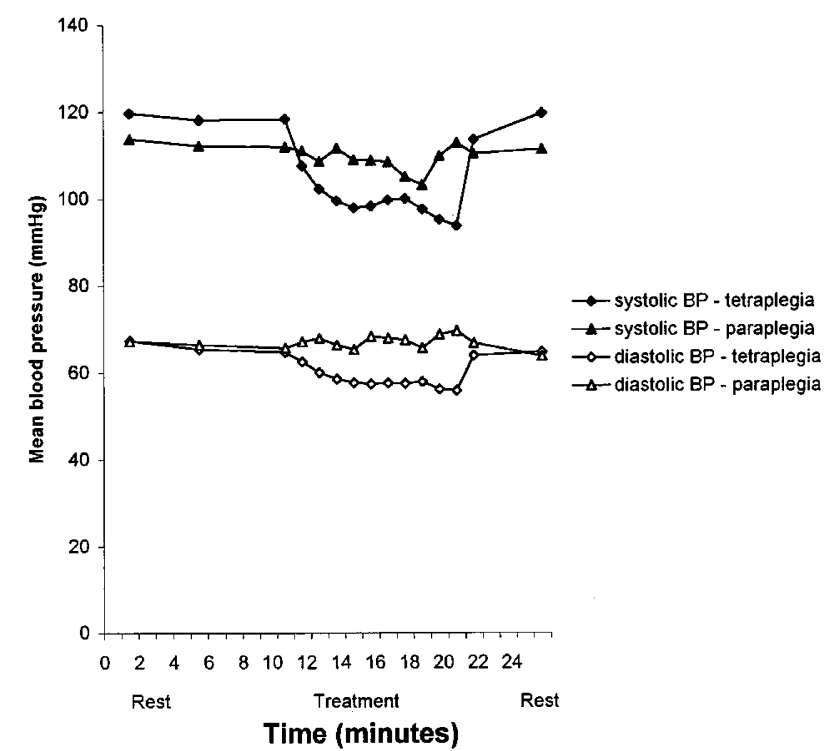

Figure 2 Mean systolic and diastolic blood pressure, comparing patients with tetraplegia $(n=10)$ to those with paraplegia $(n=4)$

60 of the 95 treatments $(63.2 \%)$ that patients with tetraplegia received, compared to one of the 34 treatments $(2.9 \%)$ that patients with paraplegia received.

As there appeared to be an association between $\mathrm{OH}$ and tetraplegia, it was decided to further investigate the impact of the completeness of the lesion as classified by the ASIA score for the 10 patients with tetraplegia. Of the 10 patients with tetraplegia, three were classified as complete tetraplegia (ASIA A) and the remaining seven patients had incomplete tetraplegia (ASIA B or D). Decreases in systolic and diastolic BP were found for patients with both complete and incomplete tetraplegia, all of which were of a magnitude indicative of $\mathrm{OH}$. However, the fall in BP appeared to be more rapid for the patients with complete tetraplegia.

The impact of the length of time in bed prior to commencement of mobilisation for patients with tetraplegia was also investigated. Patients with tetraplegia were divided into two groups depending on whether they stayed in bed for more or less than 14 days prior to commencement of mobilisation. Fourteen days was selected as the defining period of time because this length of bed rest has been shown to be associated with $\mathrm{OH}$ in normal subjects. ${ }^{9}$ Four patients with tetraplegia had less than 14 days bed rest prior to mobilisation (mean 7.8 days) and six patients with tetraplegia had more than 14 days bed rest prior to mobilisation (mean 19.5 days). From Figure 3, it can be seen that patients with tetraplegia who had more than 14 days bed rest showed decreases in both mean systolic and diastolic $\mathrm{BP}$ that were indicative of $\mathrm{OH}$. The four patients with less than 14 days bed rest also showed a fall in mean

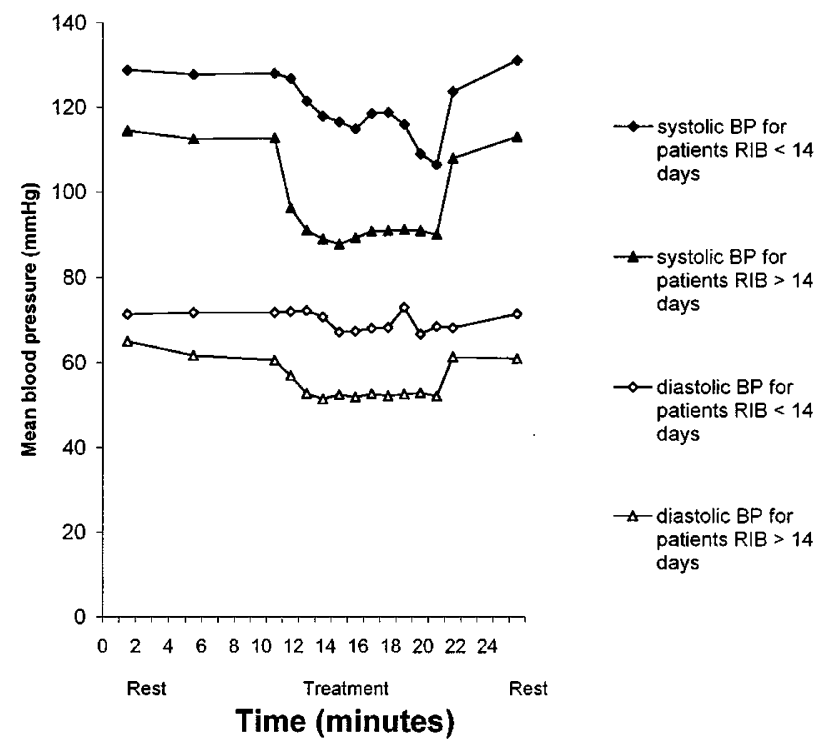

Figure 3 Mean systolic and diastolic blood pressure for the patients with tetraplegia, comparing those with less than 14 days bed rest $(n=4)$ and more than 14 days bed rest $(n=6)$ prior to commencement of mobilisation. $\mathrm{RIB}=$ rest in bed

systolic BP indicative of $\mathrm{OH}$ but only a slight fall in mean diastolic BP. Hence, patients with tetraplegia demonstrated a fall in BP indicative of $\mathrm{OH}$, regardless of the length of bed rest prior to mobilisation.

\section{Discussion}

This study found an overall prevalence of $\mathrm{OH}$, as defined by BP changes, of $73.6 \%$ over the 129 mobilisation treatments by physiotherapists that comprised the study period for 14 patients admitted to the Spinal Injuries Unit with an acute SCI. Visual signs and patient reported symptoms of $\mathrm{OH}$ accompanied these BP changes on $58.9 \%$ of occasions. Signs and symptoms were perceived as limiting treatment on $33.3 \%$ of the 129 mobilisation treatments. The prevalence of $\mathrm{OH}$ was greater for patients with tetraplegia compared to those with paraplegia, irrespective of whether the SCI lesion was complete or incomplete. The length of time that patients with tetraplegia spent in bed prior to commencement of mobilisation did not appear to have a major influence on the prevalence of $\mathrm{OH}$.

The findings of this study confirm and extend those of Mathias et $a l^{8,10}$ and Kooner et $a l^{11}$ who demonstrated similar substantial drops in mean BP for patients with complete chronic tetraplegia during tilting on a tilt bed. However, the rebound hypertension reported by Mathias et $a l^{8}$ was not seen for most of our patient sample. Further comparison is not apropriate, given that the patient sample in the present study had acute and varied levels of SCI and the positional changes used in the present study were different from those of Mathias et $a l^{8,10}$ and Kooner et al. ${ }^{11}$ 
Although a higher rate of $\mathrm{OH}$ was anticipated during the initial treatments of the 10 treatments which comprised the study period, this was not the case, with the occurrence of $\mathrm{OH}$ evenly spread over the 10 treatments. This may be due to the progression of the mobilisation treatments over the study period increasingly challenging orthostatic responses.

When considering the association between BP changes and the visual signs and patient reported symptoms of $\mathrm{OH}$, there were occasions when $\mathrm{OH}$ as defined by BP changes was detected, but signs and symptoms of $\mathrm{OH}$ were not present. The possible explanations for this include the possibility that cerebral perfusion was maintained despite a fall in systemic $\mathrm{BP}$ or that the modified definition of $\mathrm{OH}$ that was used for this study may have over-estimated the prevalence of $\mathrm{OH}$. Additionally, it appeared that some patients with stoical personalities under-reported symptoms of $\mathrm{OH}$. Another consideration is that during data collection it appeared that excessive movement of the patient's arm with the BP cuff attached, or isometric contraction of the upper $\operatorname{limb}$ muscles, resulted in large fluctuations of BP between readings. Thus, a series of $\mathrm{BP}$ readings may provide a more accurate indication of $\mathrm{OH}$, rather than basing the diagnosis on a single BP reading.

As far as the accuracy of the visual signs and patient reported symptoms of $\mathrm{OH}$ is concerned, there were four occasions (three times for patient number 1 and once for patient number 14) when signs and symptoms of $\mathrm{OH}$ were noted, but a fall in $\mathrm{BP}$ indicative of $\mathrm{OH}$ was not seen. Patient number 1 demonstrated a high level of anxiety during treatment which may have contributed to his signs and symptoms. Although it cannot be stated with certainty from the results of this study, the visual signs and patient reported symptoms of $\mathrm{OH}$ appeared to offer experienced clinicians an acceptable means of monitoring the occurrence of $\mathrm{OH}$ during physiotherapy treatment. It should also be noted that although the treating physiotherapist was unaware of the reading from the $\mathrm{BP}$ monitor, no patients lost consciousness, suggesting that the termination of treatment based on visual signs and patient reported symptoms of $\mathrm{OH}$ may be sufficient to avoid syncope.

Based on the results of this study, it is recommended that physiotherapists carefully and frequently monitor visual signs and patient reported symptoms of $\mathrm{OH}$ during treatments that involve positional change from supine to an upright position for patients with an acute SCI. The routine use of non-invasive BP monitoring may provide additional information, but may also generate spurious readings on a moment to moment basis due to excessive movement or isometric contraction of the upper limbs. As expected, while heart rate increased during mobilisation for all patients, it did not reflect the occurrence of $\mathrm{OH}$. The changes in $\mathrm{SpO}_{2}$, recorded using an ear probe, were of a small magnitude and did not provide any additional information about $\mathrm{OH}$ during mobilisation treatment.
Further study is needed to further identify characteristics that increase the risk of patients with acute SCI developing $\mathrm{OH}$. Additionally, it would be of interest to monitor cerebral blood flow as well as systemic BP during mobilisation to clarify why some patients demonstrated falls in BP without signs and symptoms of $\mathrm{OH}$. The effect of $\mathrm{OH}$ on the neurological status of acute SCI patients could also be investigated in future studies. Longitudinal studies may help in the identification of the time required for these patients to accommodate to orthostatic stresses. The most effective means of management of $\mathrm{OH}$ also needs to be studied in order to minimise the disruption to rehabilitation that may result from $\mathrm{OH}$.

\section{Conclusion}

Orthostatic hypotension as defined by BP changes occurred during $73.6 \%$ of mobilisation treatments for 14 patients who had sustained an acute SCI. Visual signs and patient reported symptoms of $\mathrm{OH}$ were often, but not always, associated with a fall in BP. Of all the treatments that comprised the study period, signs and symptoms of $\mathrm{OH}$ were perceived as limiting treatment on $33.3 \%$ of occasions. For this sample of patients, the prevalence of $\mathrm{OH}$ was higher and the fall in BP was more severe for patients with tetraplegia, regardless of whether the lesion was complete or incomplete and the number of days of bed rest prior to mobilisation

\section{Acknowledgements}

The authors would like to thank Johnson and Johnson Medical for the loan of the Dinamap ${ }^{\text {TM }}$ non-invasive monitoring and Melissa Goold, Physiotherapy Department for her invaluable assistance with data collection. Also, patients and staff of the Physiotherapy Department and Spinal Injuries Units at Royal Adelaide Hospital and Hampstead Rehabilitation Centre are thanked for their cooperation.

\section{References}

1 American Autonomic Society and American Academy of Neurology. Consensus statement on the definition of orthostatic hypotension, pure autonomic failure and multiple system atrophy. Neurology 1996; 46: 1470.

2 Blackmer J. Orthostatic hypotension in spinal cord injured patients. J Spinal Cord Med 1997; 20: 212-217.

3 Maury M. About orthostatic hypotension in tetraplegic individuals - reflections and experience. Spinal Cord 1998; 36: $87-90$.

4 Nitsche B, Perschak H, Curt A, Dietz V. Loss of circadian blood pressure variability. J Human Hypertension 1996; 10: 311 - 317.

5 El Masry WS. Physiological instability of the spinal cord following injury. Paraplegia 1993; 31: 273-275.

6 Maynard FM et al. International standards for neurological and functional classification of spinal cord injury. Spinal Cord 1997; 35: $266-274$. 
7 Guttmann L, Munroe AF, Robinson R, Walsh JJ. Effect of tilting on the cardiovascular responses and plasma catecholamine levels in spinal man. Paraplegia 1963; 1: 4-18.

8 Mathias CJ, Christiensen NJ, Frankel HL, Peart WS. Renin release during head-up tilt occurs independently of sympathetic nervous system in tetraplegic man. Clin Sci 1980; 59: 251-256.

9 Vallbona C, Lipscomb HS, Carter RE. Endocrine responses to orthostatic hypotension in quadriplegia. Arch Phys Med Rehabil 1966; 47: 412-421.
10 Mathias CJ et al. Plasma catecholamines, plasma renin activity and plasma aldosterone in tetraplegic man, horizontal and tilted Clin Sci Mol Med 1975; 49: 291-299.

11 Kooner JS et al. Haemodynamic, hormonal and urinary responses to postural change in tetraplegic and paraplegic man. Paraplegia 1988; 26: $233-237$ 